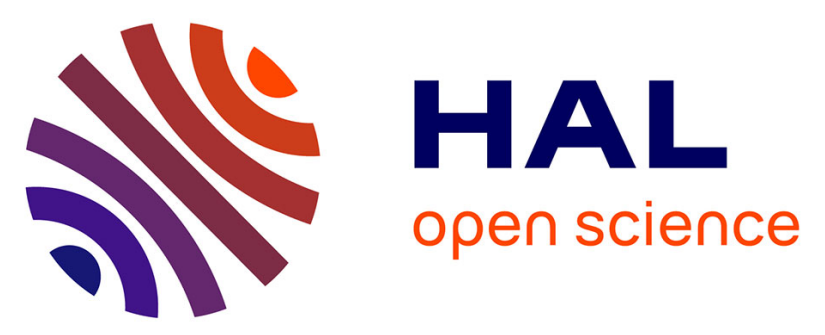

\title{
Customer attractiveness, supplier satisfaction and preferred customer status: Introduction, definitions and an overarching framework
}

Holger Schiele, Richard Calvi, Michael Gibbert

\section{- To cite this version:}

Holger Schiele, Richard Calvi, Michael Gibbert. Customer attractiveness, supplier satisfaction and preferred customer status: Introduction, definitions and an overarching framework. Industrial Marketing Management, 2012, 41 (8), pp.1178-1185. 10.1016/j.indmarman.2012.10.002 . hal-00948480

\author{
HAL Id: hal-00948480 \\ https://hal.science/hal-00948480
}

Submitted on 18 Feb 2014

HAL is a multi-disciplinary open access archive for the deposit and dissemination of scientific research documents, whether they are published or not. The documents may come from teaching and research institutions in France or abroad, or from public or private research centers.
L'archive ouverte pluridisciplinaire HAL, est destinée au dépôt et à la diffusion de documents scientifiques de niveau recherche, publiés ou non, émanant des établissements d'enseignement et de recherche français ou étrangers, des laboratoires publics ou privés. 
Customer attractiveness, supplier satisfaction and preferred customer status:

Introduction, definitions and an overarching framework

Industrial Marketing Management, 2012, Vol.41, n8, 1178-1185

\author{
Holger Schiele (corresponding author) \\ University of Twente \\ Hallenweg 17, NL-7522 NH Enschede - The Netherlands \\ Tel.: +31534895615 \\ Fax: +31534892159 \\ E-mail: h.schiele@utwente.nl
}

\author{
Richard Calvi \\ IREGE \\ University of Savoy \\ 4, chemin de Bellevue, BP 80439, \\ 74944 Annecy le Vieux CEDEX - France \\ Tel: +33 682897721 \\ E-mail: Richard.calvi@univ-savoie.fr
}

\begin{abstract}
Michael Gibbert
Professor of Marketing
\end{abstract}

Director, Ph.D. Program in Communication Studies Institute of Marketing and

Communication

University of Lugano

Via Giuseppe Buffi 13

$\mathrm{CH}-6904$ Lugano

Tel.: +41(0)58 6664727

Fax: +41 (0)58 6664647

E-mail: Michael.gibbert@usi.ch 


\begin{abstract}
Industrial markets are frequently characterized by an oligopolistic market structure. As a result, suppliers may become highly selective with respect to decisions that involve collaborating with certain customers. Buying firms must therefore be more attractive than their rivals to obtain opportunities to collaborate with these selective suppliers. This apparently counterintuitive inversion of the classical marketing approach (that is, relationships that involve buyers competing for suppliers rather than the other way round) constitutes the foundation of the special issue that is introduced in this paper. In this paper, we present key terms and propose a model of preferred customership that uses a social exchange perspective to link customer attractiveness, supplier satisfaction and preferred customer status. The papers that contribute to this special issue are introduced within the context of this framework. Finally, this paper concludes with suggestions for future research directions.
\end{abstract}

\title{
Keywords
}

Customer attractiveness, supplier satisfaction, preferred customer, social exchange theory, industrial marketing, purchasing

\section{Research highlights}

- Firms benefit from being a preferred customer of key suppliers, thus enjoying privileged resource allocation by their suppliers.

- Research on customer attractiveness has been propelled by a fundamental change in supply chain organization that allocates responsibilities to suppliers following the core competence movement and the trend to open innovation. At the same time, supplier scarcity poses problems of its own.

- Customer attractiveness, supplier satisfaction and preferred customer status are linked in a "cycle model of preferred customership". This model is rooted in social exchange theory, but expands it by not only discussing continuation or discontinuation of a relationship, but by differentiating between two levels of continuing industrial exchange relationships: as regular customer or as a preferred customer.

- Research on customer attractiveness, supplier satisfaction and preferred customer status still has to be considered being in its infancy, but the special issue which is introduced by this paper, advances our understanding by presenting concepts, reviews and empirical evidence. 


\section{Researching the "other side": shifting the burden of attractiveness from the supplier to the customer}

Commonly, both academics as well as practitioners approach buyer-supplier relations with the assumption that to successfully sell products or services, suppliers attempt to become as attractive as possible to (potential) buyers. In the current special issue, we explore another perspective, namely, the phenomenon of buyers that attempt to obtain the best resources from sellers by striving to become more attractive to suppliers. This scenario represents a counterintuitive inversion of the classical marketing approach (that is, in this scenario, buyers are competing for suppliers, rather than the converse interactions). The ultimate objective of this exploration is to provide firms with insights regarding how they can achieve preferred customer status with their core suppliers and thereby gain competitive advantages relative to competing buyers by deriving greater benefits from suppliers' resources and capabilities. "A firm has preferred customer status with a supplier, if the supplier offers the buyer preferential resource allocation. This can be accomplished in several ways. A supplier may dedicate its best personnel to joint new product development, customise its products according to the customer's wishes, offer innovations or even enter into an exclusivity agreement. The supplier might also ensure privileged treatment if bottlenecks occur due to constraints in production capacity" (Steinle \& Schiele, 2008, p. 11). The key issue with respect to firms competing not only on the sales market but also on the supply market is that "really good" suppliers are in short supply (Cordón \& Vollmann, 2008).

At least two primary motives may have driven the recent increase in research that addresses customer attractiveness: 1) a fundamental change in supply chain organization that allocates increasing responsibilities to suppliers, which has coincided with 2) a reduction of suppliers in many business-to-business markets, i.e., supplier scarcity. The core competence movement has caused many activities that were formerly performed in-house to be outsourced to suppliers (Prahalad \& Hamel, 1990). The 1990s also saw a shift in the typical process of innovation generation from a closed, laboratory-centered model to an open, networkembedded model for innovation. A panel study that surveyed top R\&D-intensive firms found that only $22 \%$ of these firms relied heavily on external partners for innovation in the early 1990 s but that this share had grown to $85 \%$ by the end of that decade (Roberts, 2001). Since the turn of the century, open innovation has become a buzz word. The growth of this model has been propelled, among others, by the increasing competence levels of suppliers (Chesbrough, 2003). Given this phenomenon, to increase the scope of possible innovation, it has become increasingly important for firms to secure the best suppliers for collaborative development projects (Brem \& Tidd, 2012). However, actors have constraints on the resources that they can devote to any particular endeavor and "may only have the time and 
resources to form and satisfy the expectations of a limited number of alliances. By making choices to ally with some partners, others are ipso facto excluded" (Gulati, et al., 2000, p. 210). Firms may not wish to belong to that group of "ipso facto excluded" customers.

Moreover, in 2011, several events occurred that disrupted supply chains, stimulating further research into this topic; in particular, these events included a tsunami that damaged many coastal production facilities in Japan, a flood in Thailand and the "Arab spring", i.e., political turmoil in several countries that affected supply security. During these types of events, questions arose regarding which customers would obtain the remaining stores of scarce materials that suppliers had sequestered in safe locations and which customers would be the first to obtain new supplies as production slowly ramped up following the initial disruption. A similar situation of allocation, i.e., a situation in which suppliers have the opportunity to select customers, occurs during boom phases. Once again, it has been demonstrated that preferred customers are the beneficiary of these types of situations and are able to take advantage of their status to achieve market share gains (Schiele, 2012). Extreme situations, such as environmental risks that interrupt the supply chain or boom phases that create a seller's market, reveal an underlying challenge of certain markets: the presence of a low number of suppliers. In these markets, each supplier must make decisions regarding which customers to serve and to what extent. Supplier scarcity has been reported in several industries, such as the luxury car industry, in which producers rely on the same 30 suppliers for components of Mercedez E-class, Audi A6 and BMW 5 automobiles (Wagner \& Bode, 2011); the biotech field (Powell, et al., 1996); software production (Lavie, 2007); or the railway industry (Schiele, 2008). For many types of industrial materials, no more than two or three leading suppliers remain in the market. As a result, these suppliers often become highly selective and do not dedicate their resources equally to all of their customers. Williamson (1991) argues that a supplier generally "responds first to the needs of his preferred customers" (p. 83), whereas less preferred customers are "forced to wait in a queue" (p. 81). In cases of uncertainty, suppliers first attend to their strategically important preferred customers and only subsequently conduct business with their regular customers. The contributions of Baxter (this issue) and Ellis et al. (this issue) provide large-scale empirical evidence of the relevance of this phenomenon.

As early as 1970, Hottenstein noted that "most businesses have a preferred customer's list, which may be based on past orders or expectations of future business." (1970, p. 46) Thus, buying firms are faced with the challenge of rising to the top of an important supplier's preferred customer list. The primary research question that arises from observations of competition in the supply market is how a buyer can eventually become a preferred customer of leading suppliers. To address this issue, various sub-questions must be resolved; for 
instance, the antecedents to preferential resource allocation must be identified, metrics for measuring a buyer's status with a supplier must be developed, and methods of influencing suppliers must be characterized.

The traditional perspective, which is more focused on supplier attractiveness than on customer attractiveness, fails to provide satisfactory explanations for the aforementioned phenomena of the relationships on "the other side". As a consequence, to date, little information to guide firms with respect to managing their attractiveness and reaching preferred customer status has been provided in the extant literature. There have been some first practitioner books that have touched this issue (Cordón \& Vollmann, 2008; Rudzki \& Trent, 2011; Schumacher, et al., 2008); however, as emphasized by the literature reviews in this special issue (Hüttinger, et al., this issue; Mortensen, this issue), research has only begun to provide reliable answers to the questions that were posed above. It appears clear, though, that one condition for firms to achieve preferential treatment is to have satisfied suppliers. Moving one step earlier in the chain of buyer-supplier interactions, the buying firm may need to be sufficiently attractive in the first place to induce a supplier to start a business relationship at all. The distinction between the three steps of (1.) customer attractiveness, (2.) supplier satisfaction and eventually (3.) preferred customer status can be embedded in the context of social exchange theory, which is widely used as a foundation of work that addresses attractiveness.

In the following section, we briefly elaborate on the "cycle of preferred customership", which links the three stages of customer attractiveness, supplier satisfaction and preferred customer status and served as a guideline for selecting contributions to this special issue. Concepts will be defined in ways that reflect the insights that have been gleaned from the latest contributions in this field. Subsequently, the papers of this special issue will briefly be introduced, distinguishing between conceptual and review papers and between case studies and quantitative empirical work. Finally, we will summarize what we know and what remains uncertain with respect to attractiveness research.

\section{The cycle of preferred customership: defining and linking the core concepts of this cycle using a social exchange perspective}

In the extant literature, several researchers have occasionally discussed topics that relate to the preferred customer situation. Relevant published investigations include the simulation study by Hottenstein (1970), which marginally addressed the idea that firms may use preferred customer lists to make decisions that relate to expediting. The work of Brokaw and 
Davisson (1978) suggested that purchasers should apply marketing tools to sell their firm to the supplier. Ten years later, the idea of "reverse marketing" once again arose in the work of Leenders and Blenkhorn (1988), although these researchers used a different framework. In case studies, Williamson (1991) and Moody (1992) emphasized the importance of a firm's role as a good customer for its suppliers. Notably, these sporadic publications did not reference each other; moreover, they have apparently gone unnoticed by many other researchers. For instance, according to the "Google Scholar" database, Brokaw and Davidsson's (1978) work, which appears to be the first research paper that was fully dedicated to exploring the logic underlying the preferred customer concept, was cited only three times as of 2012. Assuming that scientific progress is a cumulative process that involves each researcher building upon the findings of previous investigators (Amundson, 2004), the dearth of connections to previous studies that address the preferred customer idea may explain why this notion has been largely neglected in the research community until relatively recently. In addition, the lack of a common theoretical basis may have slowed progress in this field. Recent findings comparing citation incidences have indicated that a common theoretical basis may foster the exchange of ideas (Chicksand, et al., 2012).

Social exchange theory is frequently used as a theoretical harbor for attractiveness studies (Hüttinger, et al., this issue; Mortensen, this issue). In this special issue, for instance, six out of the eight published papers use elements of social exchange theory as a conceptual basis (Nollet et al.; Hüttinger et al.; Ellegaard; Hald; La Rocca et al. and Ellis et al.). Social exchange theory may well become a dominant theory in attractiveness studies, complementing resource-based arguments. The resource-based view is well suited for the discussion of consequences of resource allocation issues, particularly if an extended approach is adopted that addresses the resource environment external to the firm (Dyer \& Singh, 1998; Sanchez \& Heene, 1997); in contrast, social exchange theory is better suited for discussing relationship continuation issues. One reason for the popularity of social exchange theory, and the choice of this theory here, is that the core issues that are discussed by social exchange theory include questions of relationship initiation, termination and continuation (Kelley \& Thibaut, 1978). This issue is central to the process of becoming a preferred customer or, in the worst case scenario, suffering from relationship discontinuation. In fact, one of social exchange theory's pioneers emphasized the vital importance of attraction in social exchanges, stating that "processes of social attraction, without which associations among men would not occur, give rise to processes of exchange" (Blau, 1964, p. 7) 
Social exchange theory has its origins in sociology (Blau, 1964; Emerson, 1976) and psychology (Thibaut \& Kelley, 1959) but also draws on concepts from economics, such as the use of "resources", which encompass any material or immaterial good that is exchanged in an interaction between different actors (Foa \& Foa, 1980; Homans, 1958). The core explanatory mechanism of social exchange theory revolves around the relational interdependence that develops over time through the interactions of the resource exchange partners; thus, this theory is particularly suited to a business-to-business context (Cropanzano \& Mitchell, 2005; Dwyer, et al., 1987; Hallen, et al., 1991; Lambe, et al., 2001). The theory builds upon three core elements that can be linked into a cycle of preferred customership (Schiele, et al., 2010; Schiele et al., 2012b): (1.) expectations (E), which lead to the initiation of an exchange relationship; (2.) the "comparison level" $(\mathrm{Cl})$, which is the standard that is used to judge the outcome of the exchange, producing satisfaction with the relationship after the minimum criteria have been attained; and (3.) the concept known as the "comparison level of alternatives" $\left(\mathrm{Cl}_{\text {alt }}\right)$, which refers to the assumption, first stated by Thibaut and Kelley (1959), that actors will use not only absolute but also relative criteria to evaluate the outcome of an exchange relationship. This third step implies that to eventually decide upon whether a relationship should be continued, actors are influenced by the availability of alternatives. In the framework presented here, we expand on classical social exchange theory by differentiating between two levels of continuing industrial exchange relationships: as a regular customer or as a preferred customer.

Based on the assumption that buyer-supplier relationships are social exchange processes, it can be argued that customer attractiveness is based on the expectations that a supplier has towards the buyer at the moment of initiating or intensifying a business relationship. Thus, the comparison level describes an evaluation of the supplier's satisfaction with the relationship; this satisfaction reflects the outcome of the exchange relative to previously established expectations. The construction of the comparison level of alternatives $\left(\mathrm{Cl}_{\text {alt }}\right)$ refers to the decision of the supplier to award preferred status to a customer, assign a regular status to the customer or discontinue supplying the customer. Actors are expected to have a portfolio of relationships and compare their satisfaction with one relationship to each other exchange relationship that they possess. Based on a social exchange perspective, the three related concepts of customer attractiveness, supplier satisfaction and preferred customer status can thus be linked to each other in a logical way, and consistent definitions of these terms can be derived (see figure 1). 
Figure 1: The cycle of preferred customership

Customer attractiveness: inducing relationship initiation and intensification

Attractiveness issues have been discussed in terms of mutual attraction in the buyer-supplier relationship development, customer attractiveness and the strategic positioning of buyers and suppliers in portfolio models (Mortensen, this issue). This topic is a recently emerging research field; consequently, most papers that have addressed attractiveness are either theoretical in nature or based on case studies. Very few surveys have been conducted in this field; to date, these surveys have underscored the relevance of the existence of alternative relationships (Ping, 1994), tested the attractiveness of one sales and distribution channel (Anderson \& Narus, 1984) and generated the recommendation that firms should concentrate on a limited number of suppliers (Eggert, et al., 2009).

In social exchange theory, attractiveness plays an important role. It is assumed that the perception of initial attraction is particularly based on beliefs and expectations. Blau (1964) stated that an individual is attracted to another if he expects an association with this other individual to be a rewarding experience. On a more operational level, Homans (1958) and Thibaut and Kelley (1959) explained that the attractiveness of another entity is determined by the difference between the expected rewards from a relationship and the costs of being involved in this putative relationship. Thus, attractiveness involves a forward-looking orientation. In this context, Wilkinson et al. (2005) and Mortensen et al. (2008) emphasized that a relationship will only be initiated and developed if actors on both the supplier and buyer sides perceive the attractiveness of this relationship. We therefore argue the following claim: A customer is perceived as attractive by a supplier if the supplier in question has a positive expectation towards the relationship with this customer. The conditions for this perception of the supplier include an awareness of the existence of the customer and knowledge of the customer's needs.

Although the task of signaling one's needs to the market might sound trivial, this undertaking can be a challenge for many firms, particularly - but not only - for small buyers that might not even be known a priori to their potential business partners. Increasingly, instead of finished products, firms offer competences to solve problems; which adds further complexity to the development of buyer-supplier relationships (Golfetto \& Gibbert, 2006). In relationship literature, the need for sufficient awareness has been discussed (Dwyer, et al., 1987). However, awareness alone is not sufficient. A well-known customer can nonetheless be 
unattractive if there are negative expectations (and/or a lack of positive expectations) that are associated with this well-established organization. However, if the two conditions of awareness of the customer and positive expectations towards a relationship with this putative customer are met, customer attractiveness can be discussed. Mortensen (this issue) emphasized that customer attractiveness is an ex-ante construct that is based on expectations to start and to subsequently develop an exchange relationship. The ex-post evaluation of a relationship, which occurs after an exchange event has taken place, determines satisfaction. Customer attractiveness and supplier satisfaction are two distinct constructs; however, these constructs are sequentially linked to each other.

\section{Supplier satisfaction: comparing outcomes with expectations}

Research on supplier satisfaction in buyer-supplier relationships is scarce and is primarily conceptual in nature (Benton \& Maloni, 2005). Satisfaction has been marginally addressed by several authors, but few publications have focused on the satisfaction that is experienced by suppliers and tried to measure this. The first of these scarce publications, a dissertation, proposed a tool for measuring supplier satisfaction (Maunu, 2003). Another paper developed and tested a supplier satisfaction index (Essig \& Amann, 2009), Nyga et al. (2010) tested buyer and supplier models, though with very few variables, whereas Ghijsen et al. (2010) tested techniques that buyers can use to influence supplier satisfaction. These reports often were not linked to a clear theoretical foundation; as a result, they regarded satisfaction as a stand-alone construct and did not relate it to its potential antecedents and consequences of attractiveness and preferred customer status, respectively. A social exchange perspective can establish links between these concepts.

According to Thibaut and Kelley (1959), a relationship is evaluated by comparing its expected value to the actual quality of the outcomes that it achieves, i.e., the quantities of rewards and costs that a supplier faces during the course of an interaction. The discrepancies between the supplier's expectations and the value that is actually obtained through an exchange relationship determine the level of satisfaction that is experienced by the supplier (Wilson, 1995). Because there are costs that are associated with participating in an exchange relationship, social exchange theory suggests that parties will only remain in the relationship as long as satisfactory rewards continue to surpass a minimum comparison level (Homans, 1958; Lambe, et al., 2001). In accordance with this reasoning, the importance of supplier satisfaction in the discussion of what factors determine the suppliers' decisionmaking processes should be emphasized. If the quality of outcomes of a relationship remains below expectations, the supplier will be dissatisfied. In contrast, if the supplier feels that a 
relationship produces outcomes that are equal to or exceed expectations, the supplier will be satisfied. Therefore, supplier satisfaction is a condition that is achieved if the quality of outcomes from a buyer-supplier relationship meets or exceeds the supplier's expectations.

The exact nature of the expectations may vary; as long as these expectations are met, satisfaction is the outcome. This definition includes previous definitions that are based on a notion of fairness (Benton \& Maloni, 2005; Essig \& Amann, 2009); this notion may or may not be an expectation of the supplier. Important constructs in supplier evaluative judgments include expectations with respect to customer attractiveness, the degree to which these expectations are fulfilled and the resulting level of supplier satisfaction (see figure 1).

Although a minimum level of satisfaction may be required to maintain a relationship, satisfaction can rise gradually during the course of a relationship. "The assessment of outcomes is essential, since it helps parties in making decisions regarding upgrading or downgrading their relationships" (Wilson \& Mummalaneni, 1986, p. 51). Thus, suppliers can upgrade customers with whom they are particularly satisfied to preferred status and assign a regular status to the remaining customers that provide adequate satisfaction.

\section{Preferred customer status: differentiating customers}

The idea of supplier selectiveness in business-to-business markets has gained little attention in academic literature; however, in recent years, several practitioner papers regarding customer of choice have appeared (Bew, 2007; Day, 2011). With respect to empirical evidence, two case studies were presented in the early 1990s (Moody, 1992; Williamson, 1991), and another case study was reported more than a decade later (Steinle \& Schiele, 2008). The first survey results regarding this topic appear to confirm the assumption that preferred customer status can be an antecedent to supplier innovativeness and the same time have a positive impact on supplier pricing behavior (Schiele, et al., 2011). Two additional quantitative studies appear in this special issue, exposing the role that preferred customer status plays in technology access (Ellis, et al., this issue) and revealing the connections between attractiveness, satisfaction and preferential treatment (Baxter, this issue).

According to social exchange theory, there is an interesting construct that sellers use to analyze and evaluate exchange relationships with buyers; this construct, which explains preferential resource allocation to customers rather well, is the comparison level for alternatives $\left(\mathrm{Cl}_{\text {alt }}\right)$. The comparison level for alternatives is a standard that represents the average quality of outcomes that are available from the best alternative exchange 
relationship (Thibaut \& Kelley, 1959). Both $\mathrm{Cl}$ and $\mathrm{Cl}_{\text {alt }}$ must be considered with respect to the development and maintenance of sound relationships, as the outcomes of a relationship (considered as a whole) must be superior to the outcomes that are available from alternative partners (Anderson \& Narus, 1984). Over time, each party in the exchange relationship compares the outcomes from their interactions to the outcomes that are available from exchange alternatives (Lambe, et al., 2001). Thus, supplier satisfaction is revealed as a necessary but not sufficient condition for the determination of the customer's status. Although a supplier may, in principle, be satisfied by a relationship because the value that it creates matches expectations, this supplier could still discontinue the exchange if a better alternative arises and if constraints impede serving both potential customers in similar ways.

Conversely, even dissatisfied suppliers may remain in a relationship if there is an absence of available alternatives, although possibly with reduced commitment. The consideration of alternatives is an important extension of the classical satisfaction literature (Essig \& Amann, 2009; Ghijsen, et al., 2010) and requires a shift from dyadic-level analysis to network-level analysis. In essence, buyers must know which other customers their supplier is serving. A supplier's designation of a buyer as either a preferred or regular customer is dependent on the supplier's perception of the buyer's attractiveness and its satisfaction with this customer; these factors are contingent on the status of alternative players. A supplier awards a buyer with preferred customer status if this customer is perceived as attractive and if the supplier is currently more satisfied with this customer than with alternative customers. As a consequence of this satisfaction, a supplier reacts by providing privileged resource allocation to this preferred customer.

The implication is that the status that is assigned to each customer is directly linked to the supplier's intention. In particular, although the supplier's investment in a relationship with a regular customer may be low, the preferred customer is fostered and awarded favorable treatment. Thus, customer attractiveness and supplier satisfaction are the necessary conditions for achieving preferred customer status; a benevolent strategic prioritization by the supplier is the sufficient condition for attaining this status.

The circularity of attractiveness, satisfaction and resulting partner status

Ellegaard (this issue) concludes his analysis by emphasizing the circular character of attractiveness. Attractiveness is posited to grow as interactions increase between a supplier and buyer through stages of the relationship development process (Byrne \& Rhamey, 1965; Dwyer, et al., 1987). Clearly, this growth assumes not to discuss spot purchases but instead considers a continuous exchange, which is typical for a business-to-business relationship. It 
can be expected that because preferred customer status positively influences customer attractiveness - an effect that may occur because the supplier acquires a better knowledge of the customer's needs - suppliers may opt to continue or even expand the relationship with their customer of choice. A circular relationship between customer attractiveness, supplier satisfaction and preferred customer status can hence be expected. "Therefore, relationship development is not a matter of a single stimulus-response. It is more analogous to climbing a ladder." (Cropanzano \& Mitchell, 2005, p. 890) If the hypothesis of circularity holds true, it has substantial consequences: Dwyer et al. (1987) noted that eventually, "the exchange partners have achieved a level of satisfaction from the exchange process that virtually precludes other primary exchange partners" (p. 19). Using arguments that related to comparison levels, Johnson and Rusbult (1989) also implied that the hypothesis of circularity should hold, as these researchers proposed that there is a tendency to devalue alternative relationships due to the high level of satisfaction that relationship participants experience in their present relationship: "Alternatives should appear less attractive because the subject's comparison level for alternatives has been increased as a consequence of involvement in the present satisfying relationship" (Ping, 2003, p. 239).

In summary, the logical progression depicted in figure 1 involves the following aspects. In the early stages of a business relationship, the buyer must be sufficiently attractive to the supplier to begin an exchange relationship. Once this business relationship is active, the supplier will evaluate its satisfaction with the relationship, i.e., the supplier's satisfaction with the customer. It is important for buyers to understand their supplier's satisfaction levels, in particular as the supplier has a choice to discontinue the relationship or de-emphasize its efforts. The supplier's assessment of the buyer can induce the former to either discontinue the relationship, continue with a regular degree of emphasis or award preferred customer status. The intensification of the relationship that occurs after preferred customer status is awarded creates additional expectations and may further increase the attractiveness of the customer, restarting the relationship cycle between the supplier and buyer. Of course, also a vicious circle of continuously deteriorating attractiveness can be imagined. It must be noted that a regular or "discontinued" customer could again attempt to increase its attractiveness to eventually reach preferred customer status. Moreover, an analogous cycle might occur on the supplier's side, although in this paper and in the papers constituting this special issue, the perspective of the buyer is taken.

In the following section, we will briefly introduce the papers of this special issue, which are spread across the dimensions of the cycle of preferred customership. 


\section{Introducing the contributions to this special issue: Concepts,}

\section{reviews, cases and quantitative tests}

The papers for this special issue were selected based on their methodological rigor, relevance and contribution to theory development, with the objective of achieving balanced contributions across the entire cycle of preferred customership. In total, 25 papers were received; 16 of these papers were subjected to a double-blind review process, 10 of these papers then received a second review, and eight eventually could be accepted. The papers that appear in this special issue begin from conceptual and review papers and transition to reports on theory testing.

The first paper, which is by Nollet, Rebolledo and Popel (this issue), provides a complete conceptual model of how preferred customer status could be achieved and proposes several tactics for achieving this purpose. A particular feature of the model that is presented in this paper is the addition of a "sustainability loop", which reminds both scholars and practitioners that preferred customer status, once achieved, must continuously be maintained and "reearned". Each of the four steps in this paper's model is accompanied by a checklist of practical uses that compiles various suggestions regarding how to progress forward. The next contribution, which is by Hüttinger, Schiele and Veldman (this issue) also addresses the full cycle of attractiveness but provides a literature review of customer attractiveness, supplier satisfaction and papers that elaborate on preferred customer status. Through their review process, the authors isolate the drivers that are antecedents of preferred customership and demonstrate how the achievement of attractiveness requires a crossfunctional effort of the buying firms.

Given that one purpose of special issues is to provide interested scholars with the chance to quickly obtain knowledge regarding the state-of-the-art in a field, reviews are an almost obligatory element of these issues. The aforementioned first review in this special issue is complemented by a more specialized review by Mortensen (this issue) who presents a "complete literature review on attractiveness". In addition to reviewing customer attractiveness to the supplier, Mortensen further addresses attraction not only with respect to buyer-supplier relationship development but also in the context of the management of portfolios and key accounts. He advocates for treating (ex-ante) attractiveness as a concept of its own that clearly differs from the (ex-post) satisfaction that may occur in a business relationship once an exchange has taken place.

One revelation of Mortensen's literature review is that in attractiveness studies, there is a predominance of meso-approaches at the firm level and a relative neglect of microapproaches, i.e., between individual actors in the dyad. This special issue contributes to 
addressing this deficiency: the next two papers, which include one article by Ellegaard (this issue) and one article by Hald (this issue), examine attractiveness on a micro-level. Ellegaard's conceptual contribution highlights the cyclical character of attractiveness and thereby suggests that attractiveness forms in an evolutionary way. In contrast, Hald's case study stresses the importance of major events for shaping perceptions of attractiveness and satisfaction. Future research may provide the interesting opportunity to observe which of these different models better explains the underlying phenomenon. In particular, the practical implications of these models could differ. If attractiveness and satisfaction are predominantly influenced by events, then these events should be planned and managed. However, if an evolutionary approach prevails, then organizations may have to devote greater attention both to the day-to-day behavior of the employees who interact with suppliers and to operational excellence.

The final block of papers consists of research that is based on quantitative empirical work. In contrast to previously published studies, these papers do not ask for a purchaser's perceptions but instead survey the suppliers. La Rocca, Caruana and Snehota (this issue) investigate various facets of customer attractiveness among suppliers and develop and test a scale that comprises four factors called "development potential", "intimacy", "relational fit" and "profitability". Given the scarcity of empirical research in this field, these constructs could facilitate further investigations of this topic by providing appropriate measurement instruments. The next paper, by Baxter (this issue), also relies in part on new measurements, such as its preferred customer construct. To the best of our knowledge, this study by Baxter is the first large-scale test that jointly addresses attractiveness, satisfaction and preferred customer treatment. Interestingly, in Baxter's study, supplier satisfaction is not directly linked to preferred customer treatment; instead, this relationship is fully mediated by supplier commitment. Notably, Baxter further provides the first empirical evidence for the difference between commitment (which could even be an aspect of corporate culture, i.e., it could be assumed that a customer-centric firm demonstrates a higher commitment to all of its clients than a more inward-oriented organization) and preferred customer treatment (which results from a comparison between a customer of interest and diverse other customers that a vendor may have). The last paper, by Ellis, Henke and Kull (this issue), is the only study in this issue to provide empirical evidence of the benefits that preferred customer status may generate. In particular, these researchers reveal preferred customer status as an antecedent to technology access. Surprisingly, they did not find support for the hypothesis that a high share of sales with a supplier automatically makes the buyer a preferred customer. This finding encourages small- and medium- sized firms to strive to achieve preferred customer status and simultaneously alerts large corporations that their size alone may not be sufficient to ensure privileged treatment. 
By providing these insights, this special issue has inventoried the state-of-the-art in the field through reviews, contributed to the structure of investigations into this field through conceptual contributions and advanced our understanding regarding the empirical content of the phenomenon of preferred customership. However, this exploration may be regarded as only the beginning of a journey. Therefore, the last section of this paper will discuss certain avenues for the further development of this field.

\section{Conclusions and research directions: a phenomenon requiring} purposeful management

What do we know about "the other side"? First and foremost, it is evident that attractiveness issues are real and measurable phenomena in business-to-business relationships rather than merely theoretical constructs. Baxter (this issue) and Ellis et al. (this issue) provide evidence for the assumption that suppliers differentiate between their customers and that this choice affects the performance level that a customer can expect from its supplier. Thus, further enquiries expanding our understanding of attractiveness are likely to be rewarding.

A finding that clearly emerges is that three different stages can be distinguished in the cycle of preferred customership: customer attractiveness, supplier satisfaction and preferred customership itself. Each of these stages has its own logical considerations and empirical manifestations, but these stages are clearly sequentially linked to each other. It is thus apparent that three streams of literature that had previously been largely uncoupled are actually supportive of each other and can be linked.

One striking finding from the research in this issue with respect to the findings and gaps in the current knowledge of supplier satisfaction is that selling firms may benefit from better tools to categorize their (potential) customers; to date, only a small number of portfolio models for this type of categorization have been proposed (Mortensen, this issue). In supplier satisfaction research, thus, a clear target would be to proceed with the development of theoretically and empirically validated instruments for customer evaluation (le Dain, et al., 2011). In addition, a new set of management practices to influence supplier satisfaction must be developed. The analysis of both failures to achieve supplier satisfaction, which could proceed in accordance with the typology of mismatches that Hald (this issue) proposes, and the dissolution of relationships (Helm, et al., 2006; Yang, et al., 2012) could also prove to be a rewarding path for future research.

The preferred customer logic requires at least an indirect shift from an analytical perspective of dyads to the assessment of networks of customers that compete in supply markets for the 
prime attention of the same set of suppliers. The acquisition of a better understanding of the dynamics in supply markets is a challenging task; however, this investigation could prove useful, supporting the recent growth of interest in the field of competitive dynamics. Competitive dynamics is a field of strategic management research that analyzes the actions that specific firms take during competitions with specific rivals (Chen \& Miller, 2012).

Attractiveness research can be conducted at three levels of analysis: the micro (individual actors), meso (firm and portfolio level) and macro level (entire networks and countries) (Dopfer, et al., 2004; Steinle, 2005). One enduring question is to determine the explanatory power of each level of analysis. For instance, one issue that could be addressed is whether individuals in their micro-dyads establish the policies of firms towards each other or whether preferred customers are defined by corporate planning and discussions of portfolio issues.

We would like to emphasize that to date, the macro level has been relatively unexamined in attractiveness studies. However, cross-cultural studies of supplier evaluation suggest that better evaluations are received by domestic suppliers than by international suppliers (Callahan, 2000; Homburg, et al., 2002; Schiele \& Ebner, 2013). It appears reasonable to postulate that the converse relationship might also hold; in other words, firms might find it easier to become a preferred customer of their domestic suppliers because suppliers may evaluate domestic customers more favorably than international customers.

Most of the contributions that have been discussed above and in previously published research elaborate on ways for buyers to be attractive, achieve supplier satisfaction and become a preferred customer; however, these studies do not particularly focus on the purpose of this effort (Hüttinger, et al., this issue). Certain research has been performed to examine the contribution of preferred customership to accessing the technologies and innovation initiatives of suppliers (Ellis, et al., this issue; Schiele, et al., 2011). However, preferred customership is also expected to generate benefits in production and logistics. Similarly, with respect to risk management and quality, the expectation would be that compared to regular customers, preferred customers receive higher quality supplies or quicker repairs from suppliers. We did not find conclusive studies that tested these assumptions.

Last, but not least, strategic benefits, such as the outcome of achieving preferred customer status, could overcome "purchasing's strategic irrelevance" (Ramsay, 2001a). There are nearly continual attempts to elucidate the strategic relevance of the purchasing function. However, often "important" in the sense of "big" is mistaken for "strategic" in the sense of "competitive advantage". A preferred customer from a supplier that is desirable to other buyers also achieves competitive advantages by securing maximum exclusivity with respect 
to access to the supplier in question. This phenomenon is particularly relevant if relational rents (Dyer \& Singh, 1998) can only be achieved with this supplier. The further development of this reasoning could eventually reveal an avenue for demonstrating and operationalizing the strategic relevance of purchasing (Ramsay, 2001b).

With respect to the sketch of research avenues that is presented above, one final methodological feature appears noteworthy: attractiveness research can be categorized according to the cycle stage that an investigation examines (customer attractiveness, supplier satisfaction or preferred customer status), the level of analysis that a study employs (micro, meso or macro) and the benefits that a study elucidates (e.g., innovation, production/logistics, strategic). Future research could benefit from clear positioning with respect to all of these categories; for instance, among other combinations, a supplier satisfaction study could be conducted at the meso level that targets logistics benefits. Through this type of classification, conceptually problematic redundancies may be avoided, and the scope of enquiry may be clarified. The clear positioning of research work in accordance with particular categories prevents researchers from mixing their levels of analysis unless they seek to purposefully include the investigation of the interfaces between these levels as their research proposition.

In conclusion, it is clear that customer attractiveness, supplier satisfaction and preferred customer status are delineating an emerging field of enquiry, which has demonstrated its phenomenal existence and managerial relevance; however, this field remains in its infancy with respect to its depth of understanding, its knowledge regarding contingencies, its set of tools and the guidance that it provides for managerial actions. Given the relevance of this field, the multitude of avenues for future studies that are sketched out above may encourage further promising research investigations.

Amundson, S. D. (2004). Relationships between theory-driven empirical research in operations management and other disciplines. Journal of Operations Management, 16(4), 341-359.

Anderson, J. C., \& Narus, J. A. (1984). A model of the distributor's perspective of distributormanufacturer working relationships. The Journal of Marketing, 48(Fall), 62-74.

Baxter, R. (this issue). How can business buyers attract sellers' resources? Empirical evidence for preferred customer treatment from suppliers. Industrial Marketing Management, this issue.

Benton, W. C., \& Maloni, M. (2005). The influence of power driven buyer/seller relationships on supply chain satisfaction. Journal of Operations Management, 23(1), 1-22.

Bew, R. (2007). The new customer of choice imperative: ensuring supply availability, productivity gains, and supplier innovation. Paper presented at the 92nd Annual International Supply Management Conference, Las Vegas.

Blau, P. M. (1964). Exchange and power in social life. New York: Wiley. 
Brem, A., \& Tidd, J. (2012). Introduction. In A. Brem \& J. Tidd (Eds.), Perspectives on Supplier Innovation: Theories Concepts and Empirical Insights on Open Innovation and the Integration of Suppliers. London: Imperial College Press.

Brokaw, A. J., \& Davisson, C. N. (1978). Positioning a Company as a Preferred Customer. Journal of Purchasing and Materials Management, 14(1), 9-11.

Byrne, D., \& Rhamey, R. (1965). Magnitude of positive and negative reinforcements as a determinant of attraction. Journal of Personality and Social Psychology, 2(6), 884.

Callahan, T. J. (2000). Comparisons of the Competitive Position of Canadian, Mexican, and U.S. Suppliers. Journal of Supply Chain Management, 36(4), 43-54.

Chen, M. J., \& Miller, D. (2012). Competitive Dynamics: Themes, Trends, and a Prospective Research Platform. The Academy of Management Annals, 6(1), 135-210.

Chesbrough, $\mathrm{H}$. (2003). Open innovation: the new imperative for creating and profiting from technology. Boston: Harvard Business Press.

Chicksand, D., Watson, G., Walker, H., Radnor, Z., \& Johnston, R. (2012). Theoretical perspectives in purchasing and supply chain management: an analysis of the literature. Supply Chain Management: An International Journal, 17(4), 454-472.

Cordón, C., \& Vollmann, T. E. (2008). The Power of Two: How Smart Companies Create Win: Win Customer-Supplier Partnerships that Outperform the Competition. New York: Palgrave Macmillan.

Cropanzano, R., \& Mitchell, M. S. (2005). Social exchange theory: An interdisciplinary review. Journal of Management, 31(6), 874.

Day, A. (2011). How to be a customer of choice. CPO Agenda, 6(4).

Dopfer, K., Foster, J., \& Potts, J. (2004). Micro-meso-macro. Journal of Evolutionary Economics, 14(3), 263-279.

Dwyer, R. F., Schurr, P. H., \& Oh, S. (1987). Developing buyer-supplier relationships. Journal of Marketing, 51, 11-27.

Dyer, J. H., \& Singh, H. (1998). The relational view: cooperative strategy and sources of interorganizational competitive advantage. Academy of Management Review, 23(4), 660-679.

Eggert, A., Ulaga, W., \& Hollmann, S. (2009). Benchmarking the impact of customer share in key-supplier relationships. Journal of Business \& Industrial Marketing, 24(3/4), 154160.

Ellegaard, C. (this issue). Interpersonal attraction in buyer-supplier relationships: a cyclical model rooted in social psychology. Industrial Marketing Management, this issue.

Ellis, S. C., Henke, J. W., \& Kull, T. J. (this issue). The effect of buyer behaviors on preferred customer status and access to supplier technological innovation: an empirical study of supplier perceptions. Industrial Marketing Management, this issue.

Emerson, R. M. (1976). Social Exchange Theory. Annual Review of Sociology, 2, 335-362.

Essig, M., \& Amann, M. (2009). Supplier satisfaction: Conceptual basics and explorative findings. Journal of Purchasing and Supply Management, 15(2), 103-113.

Foa, E. B., \& Foa, U. G. (1980). Resource theory: Interpersonal behavior as exchange. In K. J. Gergen, M. S. Greenberg \& R. H. Willis (Eds.), Social exchange: Advances in theory and research (pp. 77-94). New York: Plenum Press.

Ghijsen, P. W. T., Semeijn, J., \& Ernstson, S. (2010). Supplier satisfaction and commitment: The role of influence strategies and supplier development. Journal of Purchasing and Supply Management, 16(1), 17-26.

Golfetto, F., \& Gibbert, M. (2006). Marketing competencies and the sources of customer value in business markets. Industrial Marketing Management, 35(8), 904-912.

Gulati, R., Nohria, N., \& Zaheer, A. (2000). Strategic networks. Strategic Management Journal, 21(3), 203-215.

Hald, K. S. (this issue). The role of boundary spanners in the formation of customer attractiveness. Industrial Marketing Management, this issue.

Hallen, L., Johanson, J., \& Seyed-Mohamed, N. (1991). Interfirm adaptation in business relationships. The Journal of Marketing, 55(2) 29-37. 
Helm, S., Rolfes, L., \& Günter, B. (2006). Suppliers' Willingness to End Unprofitable Customer Relationships: An Exploratory Investigation in the German Mechanical Engineering Sector. European Journal of Marketing, 40(3/4), 366-383.

Homans, G. C. (1958). Social behavior as exchange. American Journal of Sociology, 63(May), 597-606.

Homburg, C., Krohmer, H., Cannon, J. P., \& Kiedaisch, I. (2002). Customer satisfaction in transnational buyer-supplier relationships. Journal of International Marketing, 10(4), $1-29$.

Hottenstein, M. (1970). Expediting in job-order-control systems: a simulation study. IIE Transactions, 2(1), 46-54.

Hüttinger, L., Schiele, H., \& Veldman, J. (this issue). The drivers of customer attractiveness, supplier satisfaction and preferred customer status - a literature review. Industrial Marketing Management, this issue.

Johnson, D. J., \& Rusbult, C. E. (1989). Resisting temptation: Devaluation of alternative partners as a means of maintaining commitment in close relationships. Journal of Personality and Social Psychology, 57(6), 967.

Kelley, H., \& Thibaut, J. (1978). Interpersonal relations: A theory of interdependence: Wiley New York.

La Rocca, A., Caruana, A., \& Snehota, I. (this issue). Measuring customer attractiveness. Industrial Marketing Management, this issue.

Lambe, C. J., Wittmann, C. M., \& Spekman, R. E. (2001). Social exchange theory and research on business-to-business relational exchange. Journal of Business-toBusiness Marketing, 8(3), 1-36.

Lavie, D. (2007). Alliance portfolios and firm performance: A study of value creation and appropriation in the US software industry. Strategic Management Journal, 28(12), 1187-1212.

le Dain, M., Calvi, R., \& Cheriti, S. (2011). Proposition of a tool to evaluate customer's performance in collaborative product development with suppliers. International Journal on Interactive Design and Manufacturing, 5(2), 73-83.

Leenders, M. R., \& Blenkhorn, D. L. (1988). Reverse marketing: the new buyer-supplier relationship. New York etc.: Free Press.

Maunu, S. (2003). Supplier Satisfaction: The Concept and a Measurement System: A Study to Define the Supplier Satisfaction Elements and Usage as a Management Tool. Oulu: Oulu University Press.

Moody, P. E. (1992). Customer supplier integration: why being an excellent customer counts. Business Horizons, 35(4), 52-57.

Mortensen, M. H. (this issue). Understanding attractiveness in business relationships - a complete literature review. Industrial Marketing Management, this issue.

Mortensen, M. H., Freytag, P. V., \& Arlbjørn, J. S. (2008). Attractiveness in supply chains: A process and matureness perspective. International Journal of Physical Distribution and Logistics Management, 38(10), 799-815.

Nollet, J., Rebolledo, C., \& Popel, V. (this issue). Becoming a preferred customer one step at a time. Industrial Marketing Management, this issue.

Nyaga, G. N., Whipple, J. M., \& Lynch, D. F. (2010). Examining supply chain relationships: do buyer and supplier perspectives on collaborative relationships differ? Journal of Operations Management, 28(2), 101-114.

Ping, R. A. (1994). Does satisfaction moderate the association between alternative attractiveness and exit intention in a marketing channel? Journal of the Academy of Marketing Science, 22(4), 364-371.

Ping, R. A. (2003). Antecedents of satisfaction in a marketing channel. Journal of Retailing, 79(4), 237-248.

Powell, W. W., Koput, K. W., \& Smith-Doerr, L. (1996). Interorganizational collaboration and the locus of innovation: Networks of learning in biotechnology. Administrative Science Quarterly, 41(1), 116-145.

Prahalad, C. K., \& Hamel, G. (1990). The Core Competence of the Corporation. Harvard business review, 68(3), 79-91. 
Ramsay, J. (2001a). Purchasing's strategic irrelevance. European Journal of Purchasing \& Supply Management, 7(4), 257-263.

Ramsay, J. (2001b). The resource based perspective, rents, and purchasing's contribution to sustainable competitive advantage. Journal of Supply Chain Management, 37(3), 3847.

Roberts, E. B. (2001). Benchmarking Global Strategic Management of Technology. Survey of the word's largest r\&d performers reveals, among other trends, a greater reliance upon external sources of technology. Research Technology Management, 44(2), 2536.

Rudzki, R. A., \& Trent, R. J. (2011). Next Level Supply Management Excellence: Your Straight to the Bottom Line Roadmap. Fort Lauderdale: J. Ross Publishing.

Sanchez, R., \& Heene, A. (1997). Reinventing Strategic Management: New Theory and Practice for Competence-based Competition. European Management Journal, 15(3), 303-317.

Schiele, H. (2008). Location, location: the geography of industry clusters. Journal of Business Strategy, 29(3), 29-36.

Schiele, H. (2012a). Accessing Supplier Innovation By Being Their Preferred Customer. Research-technology Management, 55(1), 44-50.

Schiele, H., \& Ebner, A. (2013). The role of domestic and international external cluster linkages explored on the example of buyer-supplier relations in learning regions: a cross-functional assessment. European Planning Studies, in print.

Schiele, H., Veldman, J., \& Hüttinger, L. (2010). Customer attractiveness, supplier satisfaction and preferred customer status: review, concept and research agenda. Paper presented at the international IPSERA workshop on "Customer attractiveness, supplier satisfaction and customer value" in Twente, The Netherlands, 25./26.11.2010.

Schiele, H., Veldman, J., \& Hüttinger, L. (2011). Supplier innovativeness and supplier pricing: the role of preferred customer status. International Journal of Innovation Management 15(1), 1-27.

Schiele, H., Veldman, J. , Hüttinger, L., \& Pulles, N. (2012b). Towards a social exchange theory perspective on preferred customership - concept and practice. In R. Bogaschwesky, M. Eßig, R. Lasch \& W. Stölzle (Eds.), Supply Management Research. Aktuelle Forschungsergebnisse 2012 (pp. 135-151). Wiesbaden: Springer Gabler.

Schumacher, S., Schiele, H., Contzen, M., \& Zachau, T. (2008). Die 3 Faktoren des Einkaufs: Einkauf und Lieferanten strategisch positionieren. Weinheim: Wiley-VCH.

Steinle, C. (2005). Ganzheitliches Management: Eine mehrdimensionale Sichtweise integrierter Unternehmungsführung. Wiesbaden: Gabler.

Steinle, C., \& Schiele, H. (2008). Limits to global sourcing? Strategic consequences of dependency on international suppliers: cluster theory, resource-based view and case studies. Journal of Purchasing and Supply Management, 14(1), 3-14.

Thibaut, J., \& Kelley, H. (1959). The Social Psychology of Groups: New York: Wiley.

Wagner, S. M., \& Bode, C. (2011). A Credit Risk Modeling Approach to Assess Supplier Default Risk. Paper presented at the 20th IPSERA conference in Maastricht.

Wilkinson, I., Young, L., \& Freytag, P. (2005). Business mating: Who chooses and who gets chosen? Industrial Marketing Management, 34(7), 669-680.

Williamson, P. J. (1991). Supplier strategy and customer responsiveness: Managing the links. Business Strategy Review, 2(2), 75-90.

Wilson, D., \& Mummalaneni, V. (1986). Bonding and commitment in supplier relationship: a preliminary conceptualization. Industrial Marketing and Purchasing, 1(3), 44-58.

Wilson, D. T. (1995). An integrated model of buyer-seller relationships. Journal of the Academy of Marketing Science, 23(4), 335-345.

Yang, D., Sivadas, E., Kang, B., \& Oh, S. (2012). Dissolution intention in channel relationships: An examination of contributing factors. Industrial Marketing Management(in press). 
Page 21 of 22 
Figure 1

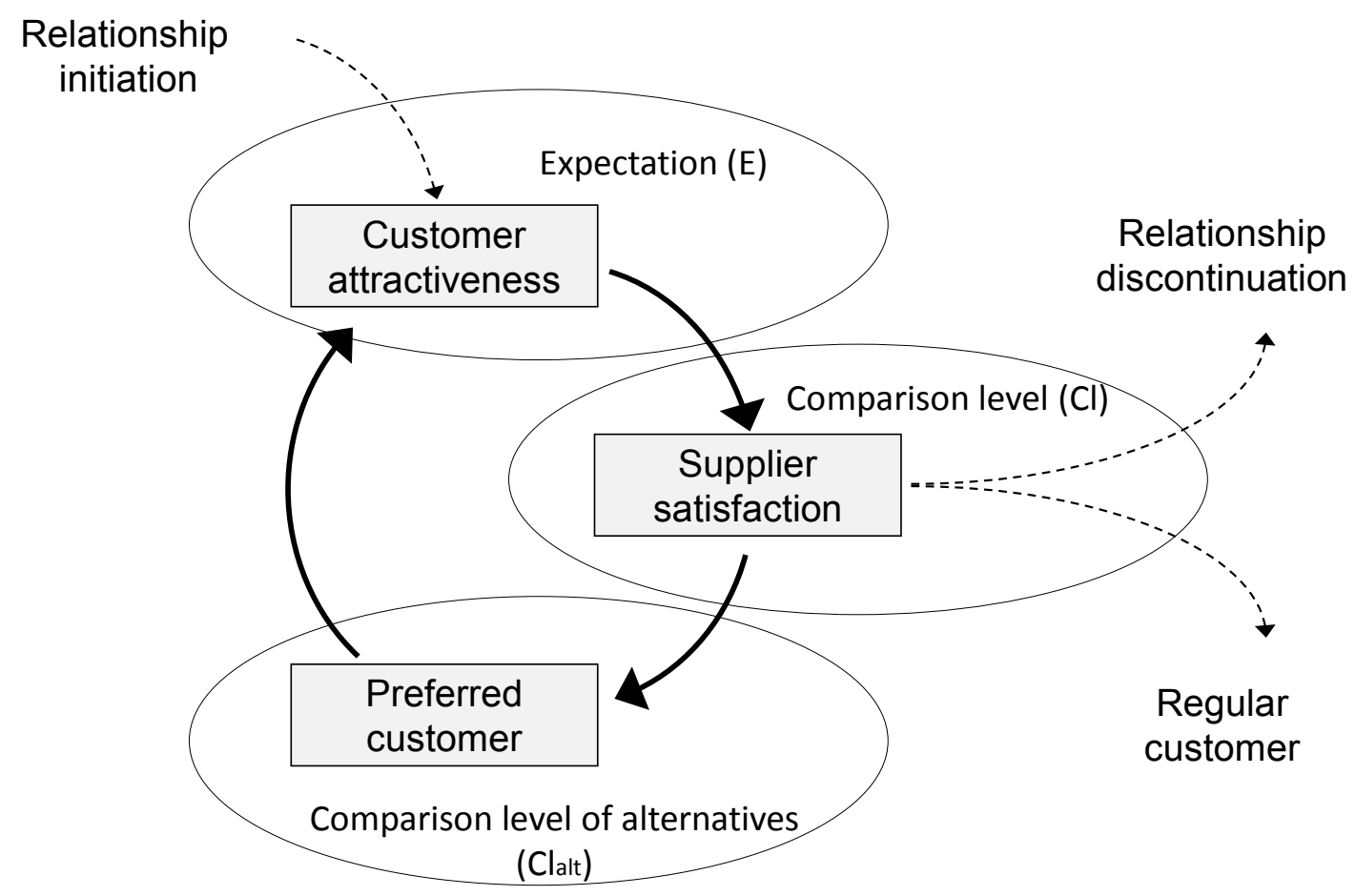

